\title{
Effects of Doping Glass Fibers on the Early Strength of Sand-Based Cemented Paste Backfill for Solid Wastes Disposal in a Coal Mine
}

\author{
Cunli Zhu $\mathbb{D}^{1,2}$ Jixiong Zhang, ${ }^{1,2}$ Zhou Nan $\mathbb{D}^{1,2}$ Meng Li, ${ }^{1,2}$ and Zhiwei He ${ }^{1,2}$ \\ ${ }^{1}$ State Key Laboratory of Coal Resources and Safe Mining, China University of Mining \& Technology, Xuzhou, \\ Jiangsu 221116, China \\ ${ }^{2}$ School of Mines, China University of Mining \& Technology, Xuzhou, Jiangsu 221116, China \\ Correspondence should be addressed to Zhou Nan; zhounanyou@126.com
}

Received 3 February 2021; Revised 4 March 2021; Accepted 3 April 2021; Published 17 April 2021

Academic Editor: Guoyang Fu

Copyright (C) 2021 Cunli Zhu et al. This is an open access article distributed under the Creative Commons Attribution License, which permits unrestricted use, distribution, and reproduction in any medium, provided the original work is properly cited.

\begin{abstract}
The mechanical strength of cemented paste backfill (CPB), especially the early compressive strength, is crucial for controlling the overlying rock movement. Therefore, improving the early compressive strength of CPB is a critical issue. In this study, the doped glass fibers' effect on the macroscopic mechanical strength and microstructural features of the sand-based CPB (SCPB) with different curing ages was analyzed. The macroscopic properties and the microstructure of SCPB were characterized experimentally and analyzed via scanning electron microscopy. The results showed that slump sizes of SCPB specimens without and with doped glass fibers were 269 and $209 \mathrm{~mm}$. Thus, doped glass fibers inhibited the SCPB transportability and significantly improved its early compressive strength. At curing ages of $1 \mathrm{~d}$ and $3 \mathrm{~d}$, the compressive strength of SCPB specimens doped with glass fibers was improved by 679 and $278 \%$, respectively, compared to the blank control group. As the curing age increased, the compressive strength improvement of the SCPB doped with glass fibers was gradually saturated. Finally, the correlation between macroscopic and microscopic properties of SCPB specimens was analyzed comparatively. Thus, the mechanism of doped glass fibers' influencing the early compressive strength of the SCPB was revealed. The research findings provide theoretical guidance for improving the SCPB early compressive strength at the mining site with the $\mathrm{CPB}$ mining technique.
\end{abstract}

\section{Introduction}

During coal mining under buildings, railways, and water bodies, the longwall-roadway cemented paste backfilling $(\mathrm{CPB})$ technique is considered very effective in controlling surface deformation [1-3]. Since fly ash and aeolian sand, as primary filling materials, cause small environmental damage, the $\mathrm{CPB}$ has been extensively applied to coal mining under conditions [4-7]. The sand-based cemented paste backfilling (SCPB) is the primary filling material used in the longwall-roadway $\mathrm{CPB}$ mining technique [8-11], which provides critical support to the overlying strata [12-15]. The SCPB strength is the key influencing factor of the overlying strata stability $[6,16,17]$. This is especially true after $1-3 \mathrm{~d}$ of the SCPB formation. At this stage, the SCPB is still located within the range disturbed by mining the backfilling working face, and the overlying strata have not yet reached the stable state [18-21]. Improving the early compressive strength of the SCPB is crucial for enhancing its early bearing performance. Given the above, the improvement of the SCPB early compressive strength has become a research priority.

At present, many scholars worldwide have conducted extensive studies on improving the compressive strength of SCPB. Thus, Feng et al. [22] improved the paste backfill's mechanical strength by adding high-concentration calcium oxide-modified copper slags in a vitrified form. Zhou et al. [23] doped the SCPB with Portland cement and fly ash as adhesives and studied the SCPB microstructure and chemical composition. They also explored the strength formation mechanism of SCPB. Y1lmaz et al. [24] doped construction waste powders into $\mathrm{CPB}$ and studied its durability and microstructural changes at different curing ages. The experimental results confirmed the applicability of 
construction wastes as filling materials, thus offering an effective pathway for the disposal of construction wastes. Although the above studies demonstrated the excellent improving effect on CPB's compressive strength, most of them were only concerned with the CPB's late strength, i.e., the strength after stabilization. A few of these studies have discussed the early compressive strength improvement of the SCPB after its formation.

As novel raw materials for doping, fibers combine high tensile strength, toughness, and corrosion resistance, making them very lucrative. Sivakumar et al. [25] studied the effect of metal and nonmetal fibers on the concrete's compressive strength, splitting tensile strength, and flexural toughness. They also performed a comparative analysis of the influence mechanisms of different types of fibers on concrete's mechanical strength. Lassila et al. [26] discussed fibers' influence on composite materials' mechanical strength, and fracture performance. Zhang et al. [27] conducted a comparative study of eighteen specimens from steel fiber-reinforced concrete and four specimens of ordinary concrete to study the influence of the steel fibers on the shear performance of the steel-concrete composite beam. It was reported that the doping of the steel fibers could effectively inhibit the crack propagation in the concrete slabs. In the above studies, the doping of fibers improved CPB's early strength to a certain degree. However, most scholars only investigated the CPB's shear strength but rarely discussed the CPB's early compressive strength. Improving the early compressive strength of the CPB is crucial for controlling the overlying strata that have not yet reached the steady-state. Therefore, it is important to clarify the effect of fibers on the $\mathrm{CPB}$ compressive strength.

This study is aimed to explore the early compressive strength of SCPB doped with glass fibers, to improve the early controlling effect of SCPB on the overburden strata movement. A WAW-1000D series computer-controlled servohydraulic universal testing machine was used for compressive strength testing of SCPB doped with glass fibers at different curing ages. The SCPB microstructure was examined via a scanning electron microscope. The experimental results revealed the influence mechanism of glass fibers on CPB's early strength. We also comparatively analyzed the effect of glass fiber doping on the CPB early macroscopic mechanical strength and microstructure. The research results obtained provided the experimental basis for improving the early compressive strength of SCPB by glass fiber doping.

\section{Materials and Method}

2.1. Test Materials. The SCPB specimens used in this study were mainly composed of the following raw materials: fly ash, cement, aeolian sand, quicklime, and water, which are shown in Figure 1(a). Some specimens were doped with different quantities of glass fibers as doping materials, Figure 1(b). The grade II fly ash was acquired from the powdery waste at the Datang Thermal Power Plant in Henan, China. The ordinary Portland cement with a strength grade of 32.5 \# was acquired from the Shaanxi
Shengwei Building Materials Group Co., Ltd., China. The aeolian sand was obtained from the loose sand deposits in Yulin, Shanxi Province of China, while the Hunan Yijiaxin Lime Factory (China) manufactured the quicklime.

2.1.1. Fly Ash. Fly ash was used as one of the binding material in the SCPB. The particle size and shape were of vital importance for the SCPB transportability. As shown in Figure 2(a), the fly ash particles were spherical. In Figure 3(a), the average particle size of the fly ash was $72.513 \mu \mathrm{m}$. The structural features and the particle size distribution of the fly ash were conducive to paste transportation.

2.1.2. Aeolian Sand. Aeolian sand is commonly used in SCPB as an aggregate. Its particle size distribution and chemical composition play a decisive role in the bearing capacity of SCPB. According to Figure 2(b), the particle size of aeolian sand ranged between 215.468 and $613.474 \mu \mathrm{m}$. The particle size was distributed over a large range, which was conducive to stress transfer within SCPB. As shown in Table 1, the aeolian sand was primarily composed of $\mathrm{SiO}_{2}$. Since $\mathrm{SiO}_{2}$ has high chemical stability, its presence in large quantities is favorable for improving the SCPB mechanical strength.

2.1.3. Cement. Cement was another binding material in the SCPB aimed to improve its mechanical strength. As seen in the SEM image of cement in Figure 2(c), cement particles had a rough surface, and their size distribution was nonuniform. The primary chemical components of cement were $\mathrm{SiO}_{2}$ and $\mathrm{CaCO}_{3}$. An intensive hydration reaction in the beginning could activate the fly ash.

2.1.4. Additives. Quicklime was added in a small quantity as an additive in SCPB. The particle size distribution is shown in Figure 3(d). It ranged from 9.822 to $170.064 \mu \mathrm{m}$, with an average of $66.385 \mu \mathrm{m}$. The main chemical component of quicklime was $\mathrm{CaO}$, which served as an alkali activator.

2.1.5. Glass Fibers. The doped glass fibers used in the SCPB were produced by the Hunan Xinchuang Glass Factory (China). They had the features of high tensile strength, corrosion resistance, high-temperature resistance, low price, and wide availability [28]. The basic parameters of the doped glass fibers are listed in Table 2.

2.2. Experimental Steps. The macroscopic mechanical strength and microstructural features of the SCPB specimens with different curing ages were measured using a WAW$1000 \mathrm{D}$ series computer control servohydraulic universal testing machine and a Quanta 250 scanning electron microscope, respectively. First, the glass fibers and raw materials for preparing SCPB (fly ash, aeolian sand, cement, and quicklime) were weighed, thoroughly mixed, and added to the dry material that had already been mixed. Secondly, after 


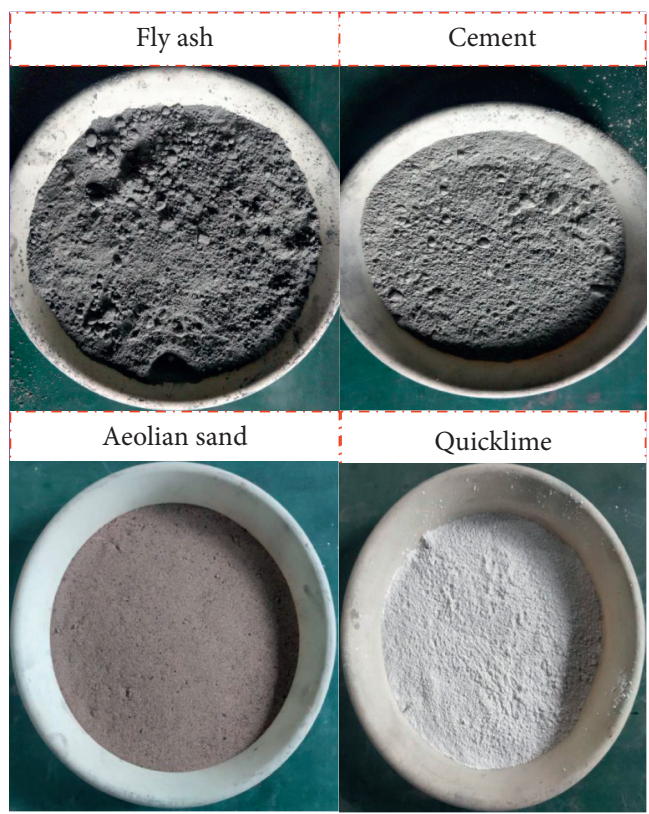

(a)

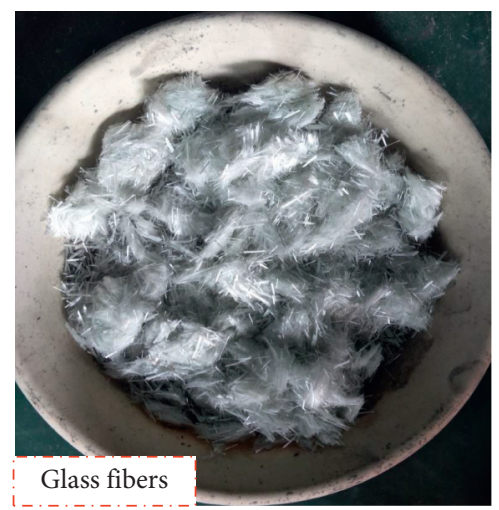

(b)

Figure 1: Test materials. (a) Raw materials for the SCPB. (b) Glass fibers.

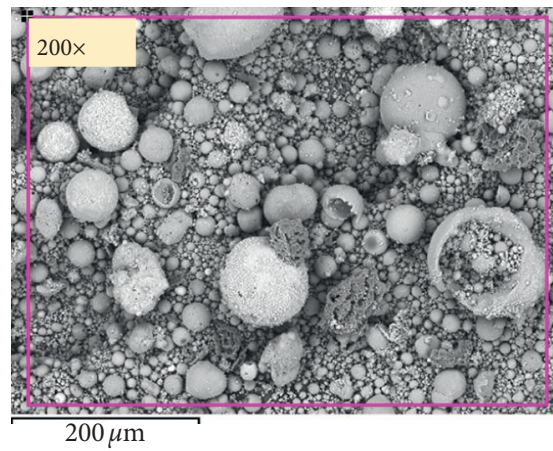

(a)

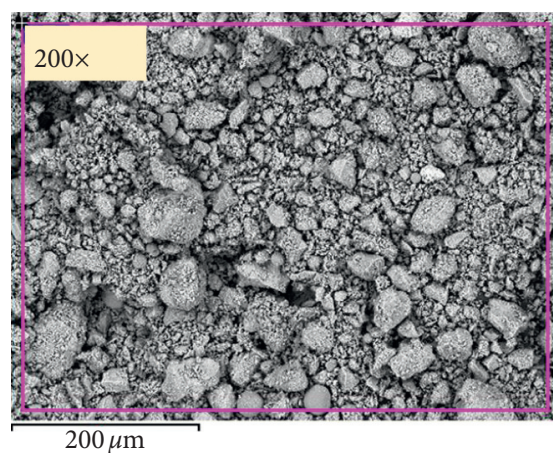

(c)

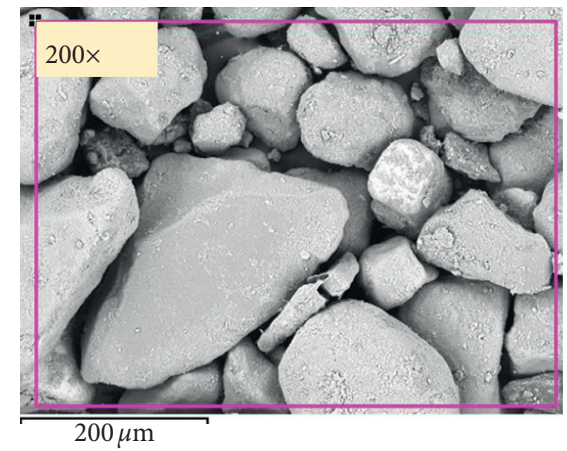

(b)

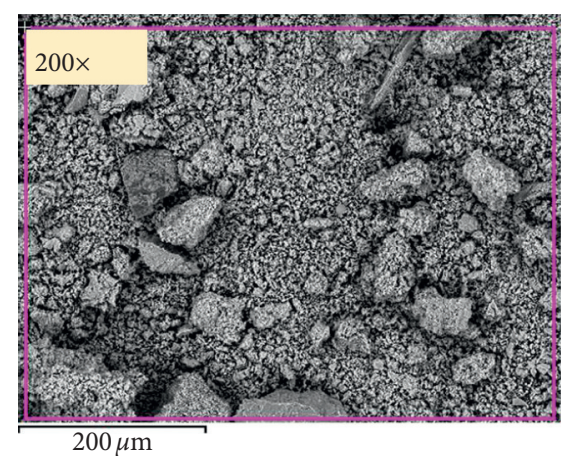

(d)

FIgURE 2: SEM/EDS analysis of the raw materials. (a) Fly ash. (b) Aeolian sand. (c) Cement. (d) Quicklime.

the dry material was evenly stirred, water was added slowly until the amount required by the mixing ratio was reached. The experimental flowchart is shown in Figure 4. The macroscopic mechanical performance testing consisted of the following steps: slurry preparation, curing, specimen preparation, and compressive strength testing. The 


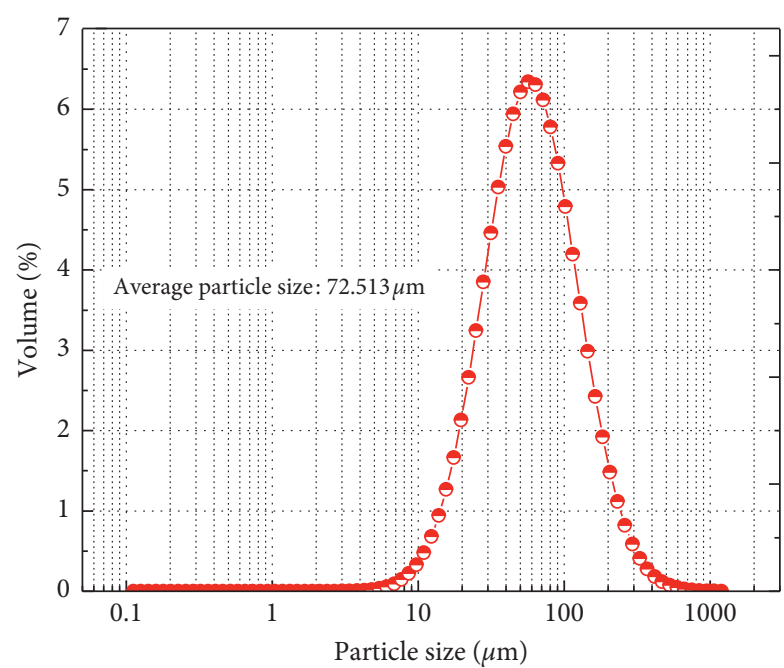

$-\odot-$ Volume

(a)

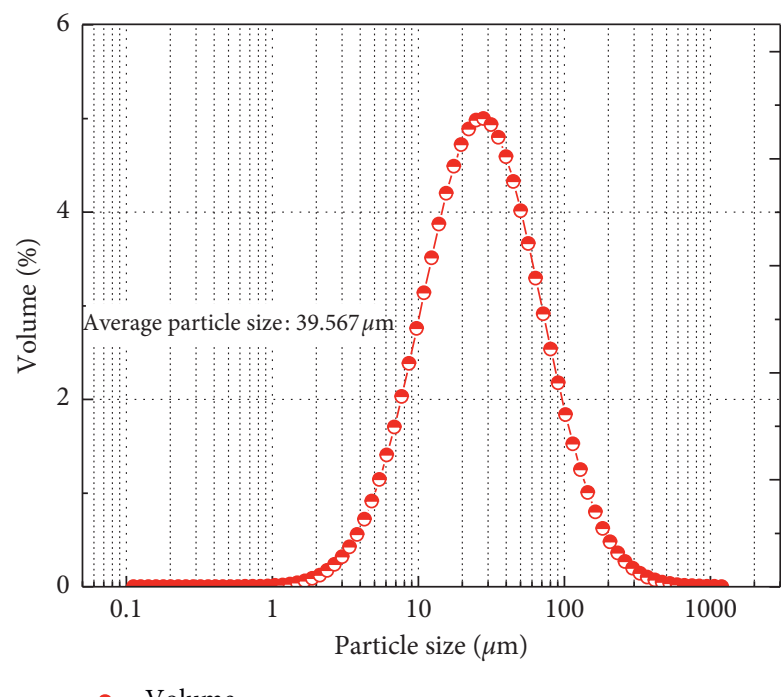

(c)

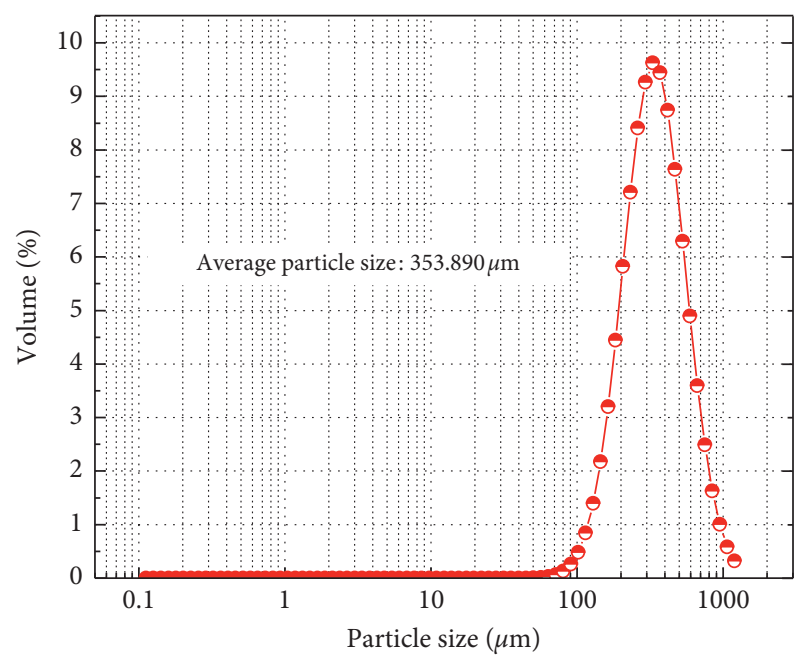

-- Volume

(b)

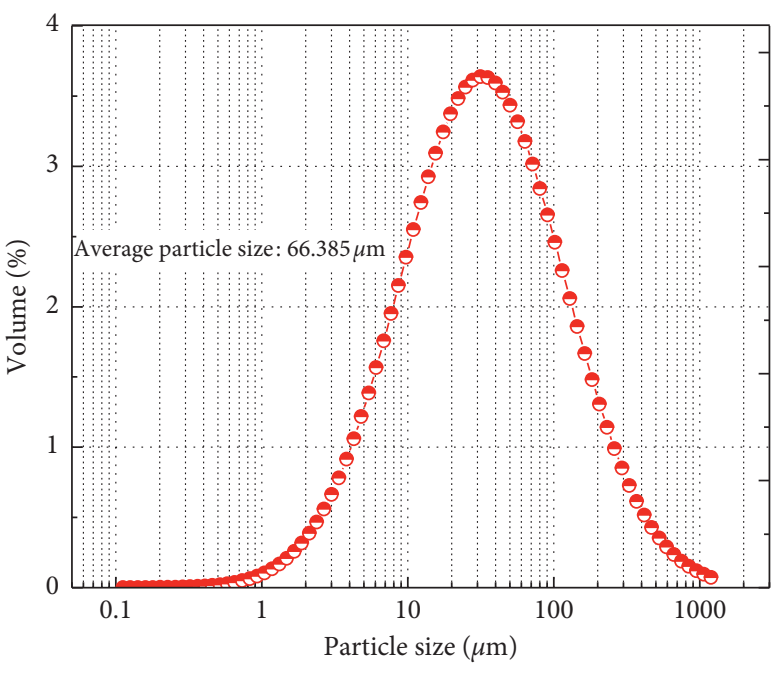

$-\odot-$ Volume

Figure 3: Particle size distributions. (a) Fly ash. (b) Aeolian sand. (c) Cement. (d) Quicklime.

TABle 1: Chemical composition of the raw materials.

\begin{tabular}{lccccc}
\hline Ingredient & $\mathrm{CaCO}_{3}$ & $\mathrm{SiO}_{2}$ & $\mathrm{MgO}$ & $\mathrm{Al}_{2} \mathrm{O}_{3}$ & 5.86 \\
\hline Fly ash & 38.22 & 45.77 & 0.16 & 0.6 & 0.68 \\
Aeolian sand & 22.28 & 56.11 & 0.6 & 16 & 13.52 \\
Cement & 24.7 & 54.97 & 1.30 & 11.5 & 13.52 \\
Quicklime & 10.14 & 21.86 & 51.5 \\
\hline
\end{tabular}

TABLE 2: The basic parameters of glass fiber.

\begin{tabular}{lcccc}
\hline Diameter $(\mathrm{mm})$ & Elongation at break $(\%)$ & Elastic modulus $(\mathrm{MPa})$ & Density $\left(\mathrm{g} / \mathrm{cm}^{3}\right)$ & Tensile strength $(\mathrm{MPa})$ \\
\hline $0.3-0.4$ & $3.3-3.6$ & $7300-8600$ & 2.49 & $3100-4650$ \\
\hline
\end{tabular}




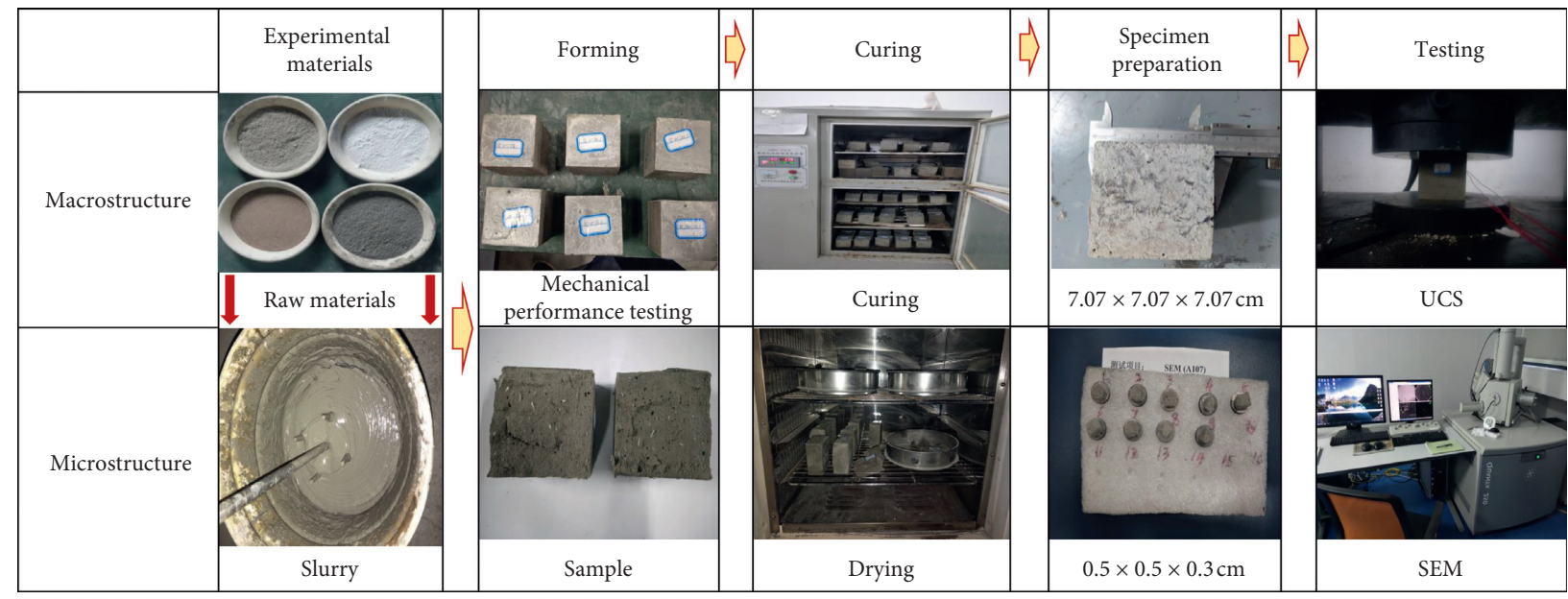

FIgURE 4: The flowchart of specimen preparation.

microstructural examination consisted of drying, specimen preparation, gold sputtering, and scanning electron microscopy (SEM) analysis.

2.3. Experimental Scheme and Method. To study the doped glass fibers' effect on the early mechanical strength, transportability, compressive strength, and microstructural features of the SCPB with and without the doped glass fibers (blank control group) were compared. The curing ages of SCPB specimens subjected to macroscopic and microstructural testing were $1 \mathrm{~d}, 3 \mathrm{~d}, 7 \mathrm{~d}, 14 \mathrm{~d}, 28 \mathrm{~d}$, and $60 \mathrm{~d}$. The SCPB concentration was $76 \%$. The length of the glass fibers doped into the SCPB was $6 \mathrm{~mm}$, and the ratio of the doped glass fibers was $1.0 \%$, as shown in Table 3 .

2.3.1. Transportability Testing. The materials were mixed according to the above ratios, as shown in Figure 5. The SCPB dry material was stirred with a mixer for 25-30 s, and then the glass fibers were slowly added. After mixing of dry material, water was continuously added to the mixing barrel according to the ratio, followed by mixing for 3-5 min to prepare the slurry. The slurry was poured into a slump test barrel with the diameters of upper and lower openings of 100 and $200 \mathrm{~mm}$, respectively, and a height of $300 \mathrm{~mm}$. After loading the materials, the slurry was compacted by stirring with a tamping rod. When the slurry reached the barrel's brim, the slurry's excess was scraped off from the upper opening to make the top flat and even. The slurry split over the brim was removed. The barrel was lifted steadily and vertically upwards in $5-10 \mathrm{~s}$ to allow the free-fall of the concrete. The concrete cone's height after the collapse was measured when the concrete was stabilized, and the slump size was calculated.

2.3.2. Mechanical Strength Testing. The thoroughly mixed slurry was poured into a cubic mold with a side length of $70.7 \mathrm{~mm}$. The concrete was cured at room temperature for $8 \mathrm{~h}$. The mold was removed, and the SCPB specimens were placed into a Y40 B curing box with a constant temperature of $20^{\circ} \mathrm{C} \pm 2{ }^{\circ} \mathrm{C}$ and constant humidity of $90 \% \pm 5 \%$. The concrete was cured for $1 \mathrm{~d}, 3 \mathrm{~d}, 7 \mathrm{~d}, 14 \mathrm{~d}, 28 \mathrm{~d}$, and $60 \mathrm{~d}$. The specimens with different curing ages were subjected to the uniaxial compression test with a loading rate of $0.5 \mathrm{~mm} / \mathrm{min}$ via a WAW-1000D series computer control servohydraulic universal testing machine. The equipment used for mechanical performance testing is shown in Figure 6. A WAW$1000 \mathrm{D}$ series computer-controlled servohydraulic universal testing machine had an accuracy grade of 0.5 and a maximum load of $1000 \mathrm{kN}$.

2.3.3. Microstructural Examination. After measuring the compressive strength of SCPB specimens with different curing ages, the specimen blocks were dried at $40^{\circ} \mathrm{C}$ in a drying oven for $24 \mathrm{~h}$. The dried blocks were cut into cubes with a length of $10 \mathrm{~mm}$, a width of $10 \mathrm{~mm}$, a height of $5 \mathrm{~mm}$, and a natural surface. The cube specimens were immobilized at the test stand with double-sided adhesive tapes. The specimens were sputter-coated with gold to increase their conductivity and facilitate the microstructure observation by SEM. Figure 7 shows the operating platform and equipment for microstructural examination. Finally, the SEM images of the specimens' natural surface were captured under the 100-3000x magnification using a Quanta 250 scanning electron microscope to observe its microstructure.

\section{Results and Discussion}

\subsection{Transportability Test}

3.1.1. Slump Test of SCPB. A slump test was performed for the SCPB specimens with and without the doped glass fibers (blank control group) to study the glass fibers' lapping effect in the SCPB. The testing results are shown in Table 4.

As shown in Table 4, three groups of slump tests were performed for the SCPB specimens without the doped glass fibers in scheme $\mathrm{I}$, and the slump was represented by $\mathrm{I}_{1}, \mathrm{I}_{2}$, and $\mathrm{I}_{3}$, respectively. Three more slump test groups were performed for the SCPB specimens doped with glass fibers in 
TABLE 3: Doping ratios of glass fibers and the CPB materials.

\begin{tabular}{lcccccc}
\hline Scheme & Glass fiber length $(\mathrm{mm})$ & Glass fiber ratio (\%) & Fly ash (\%) & Aeolian sand (\%) & Cement (\%) & Quicklime (\%) \\
\hline I & 0 & 0 & 47.5 & 39.5 & 8 & 5 \\
II & 6 & 1.0 & 46.5 & 39.5 & 8 & 5 \\
\hline
\end{tabular}

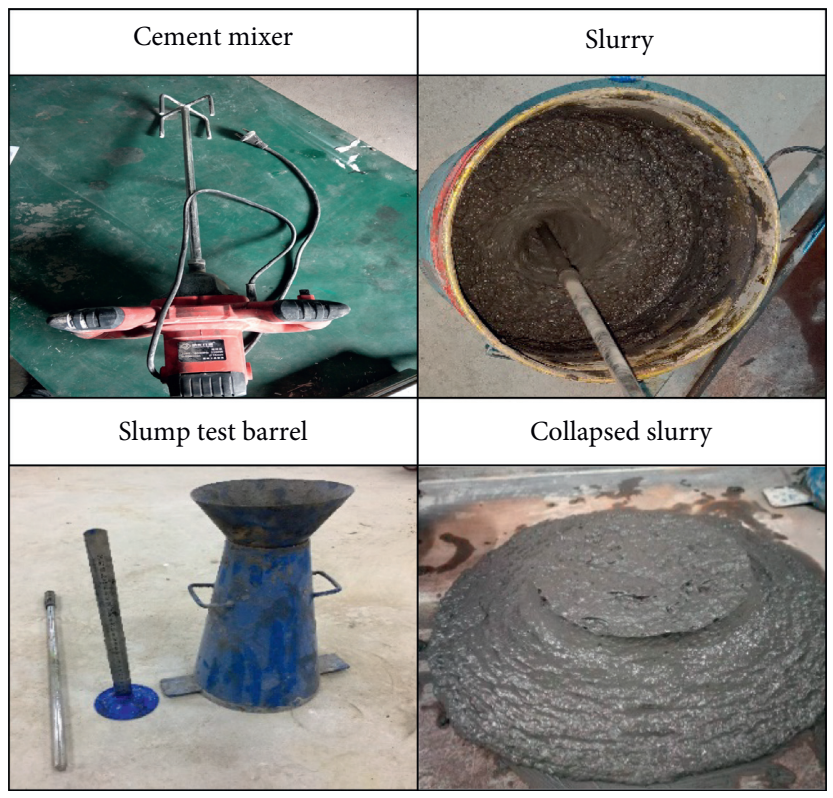

FIGURE 5: Transportability test.
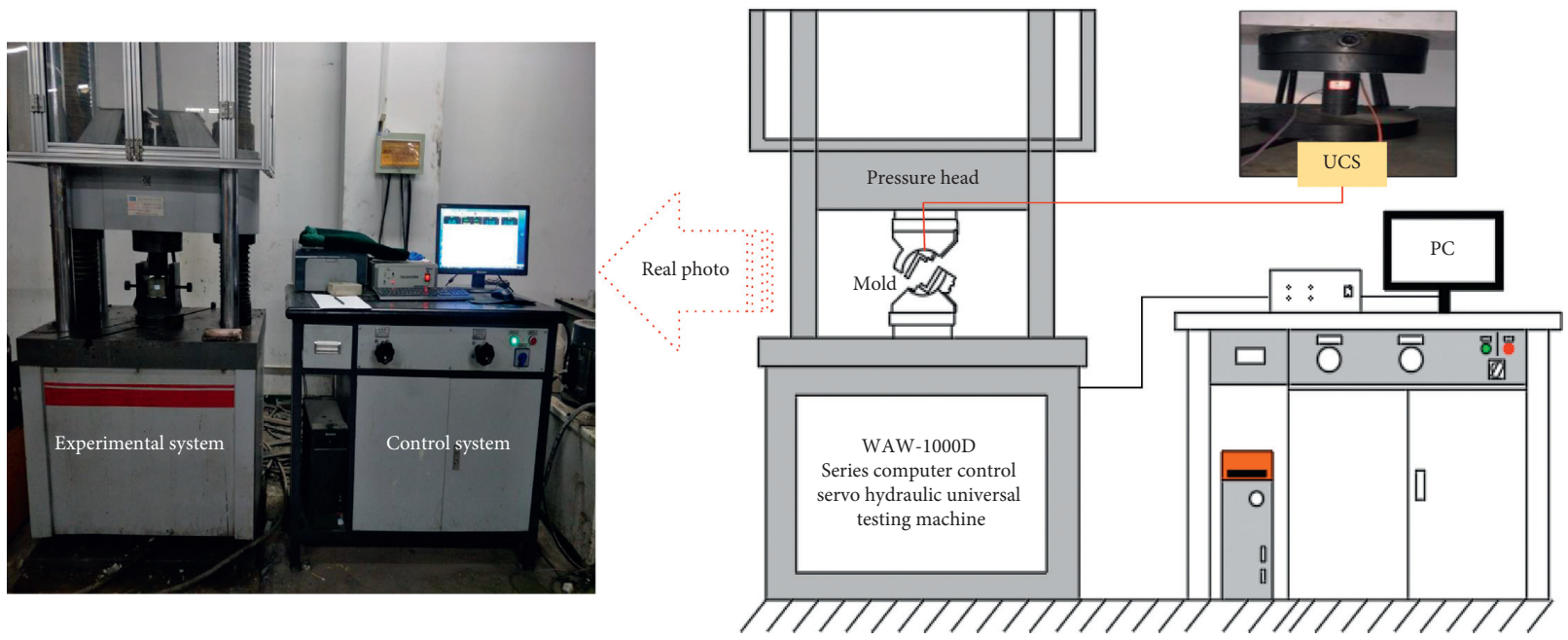

FIGURE 6: Mechanical performance testing and equipment.

scheme II, and the slump was represented by $\mathrm{II}_{1}, \mathrm{II}_{2}$, and $\mathrm{II}_{3}$, respectively.

The slump of the SCPB specimens without the doped glass fibers in scheme I was as follows: $\mathrm{I}_{1}: 261 \mathrm{~mm}, \mathrm{I}_{2}$ : $276 \mathrm{~mm}$, and $\mathrm{I}_{3}: 271 \mathrm{~mm}$, with an average of $269 \mathrm{~mm}$. The slump of SCPB specimens doped with glass fibers in scheme II was as follows: $\mathrm{II}_{1}: 207 \mathrm{~mm}, \mathrm{II}_{2}: 214 \mathrm{~mm}$, and $\mathrm{II}_{3}: 208 \mathrm{~mm}$, with an average of $209 \mathrm{~mm}$. The comparison of schemes I and II indicated that glass fibers' lapping effect inhibited the
SCPB transportability. The slump of the SCPB doped with glass fibers dropped from $269 \mathrm{~mm}$ in the blank control group to $209 \mathrm{~mm}$, i.e., by $22.3 \%$. As shown by the above test results, the two schemes' minimum slump was $207 \mathrm{~mm}$, and the maximum was $276 \mathrm{~mm}$. Both slump values satisfied engineering performance indicators for CPB mining [29].

3.1.2. Influence Mechanism of the Doped Glass Fibers on the Slump of SCPB. According to Section 3.1.1, doping with 


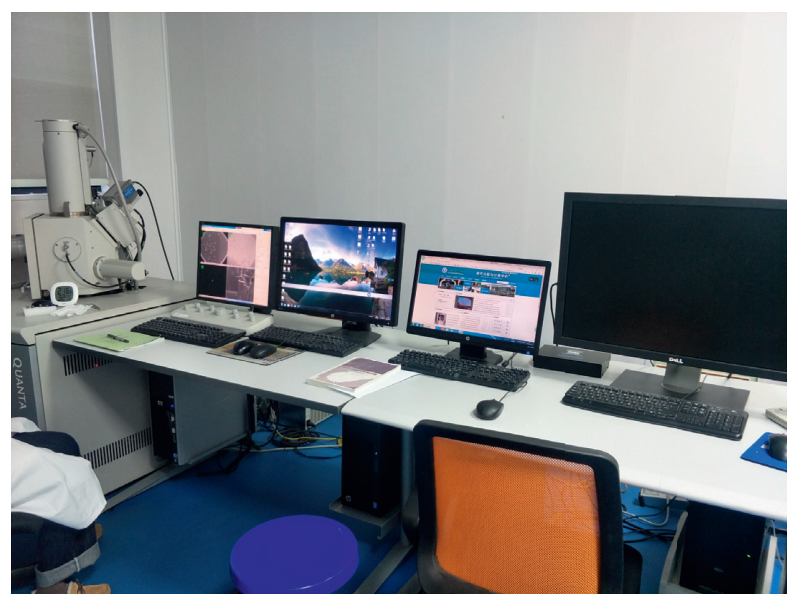

(a)

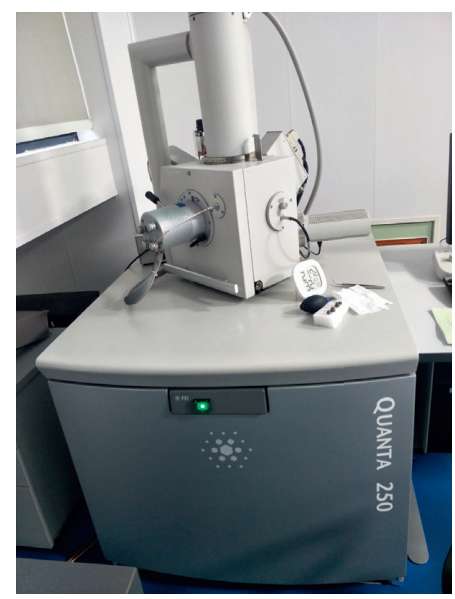

(b)

Figure 7: Microstructural examination and test equipment. (a) Operating platform. (b) Quanta 250 scanning electron microscope.

TABLE 4: Parameters of the slump testing of SCPB.

\begin{tabular}{|c|c|c|c|c|c|c|c|c|c|}
\hline \multicolumn{2}{|c|}{ Scheme } & Glass fiber length (mm) & Glass fiber ratio (\%) & Fly ash (\%) & $\begin{array}{c}\text { Aeolian } \\
\text { sand (\%) }\end{array}$ & Cement (\%) & $\begin{array}{c}\text { Quicklime } \\
(\%)\end{array}$ & Slump (mm) & $\begin{array}{c}\text { Average } \\
(\mathrm{mm})\end{array}$ \\
\hline \multirow{3}{*}{ I } & $\mathrm{I}_{1}$ & -- & -- & 47.5 & 39.5 & 8 & 5 & 261 & \multirow{3}{*}{269} \\
\hline & $\mathrm{I}_{2}$ & -- & -- & 47.5 & 39.5 & 8 & 5 & 276 & \\
\hline & $\mathrm{I}_{3}$ & -- & -- & 47.5 & 39.5 & 8 & 5 & 271 & \\
\hline \multirow{3}{*}{ II } & $\mathrm{II}_{1}$ & 6 & 1.0 & 46.5 & 39.5 & 8 & 5 & 207 & \multirow{3}{*}{209} \\
\hline & $\mathrm{II}_{2}$ & 6 & 1.0 & 46.5 & 39.5 & 8 & 5 & 214 & \\
\hline & $\mathrm{II}_{3}$ & 6 & 1.0 & 46.5 & 39.5 & 8 & 5 & 208 & \\
\hline
\end{tabular}

glass fibers inhibited the SCPB transportability and reduced the slump test's slump size. Next, the influence mechanism of the doped glass fibers on the SCPB transportability was analyzed. As shown in Figure 8, the influence pattern of the doped glass fibers' distribution status in the SPCB on the slump was reflected by the schematic diagram of the influence of doped glass fibers on the slump.

Schematic diagrams of the slump in the SCPB with or without doped glass fibers are shown in Figure 8. In the SCPB doped with glass fibers, the slump was more significant, and the slurry flowed over a more extensive area. By contrast, doped glass fibers improved the SCPB tensile resistance. The tensile force $\mathrm{F}$ had a mutual inhibitory effect on the flow of the SCPB. Besides, the glass fibers formed a backbone, which was filled by the SCPB. Therefore, the SCPB doped with glass fibers constituted an intact structure doped with glass fibers as the backbone. This structure effectively inhibited the slurry flowability, thereby reducing the slump of the SCPB.

\subsection{Macroscopic Strength of SCPB}

3.2.1. Analysis of the Influence of Glass Fibers on the Compressive Strength of SCPB Specimens with Different Curing Ages. The doped glass fibers' influence on the mechanical strength of the SCPB with different curing ages was further investigated. The uniaxial compression test was performed for the SCPB with or without doped glass fibers under different curing ages. Three identical specimens were prepared under the same curing age to minimize experimental errors. The test results are shown in Figures 9 and 10.

As shown by the uniaxial compression test results in the blank control group in Figure 9, at curing ages of $1 \mathrm{~d}$ and $3 \mathrm{~d}$, two specimens were excluded due to the outliers' appearance. Therefore, the average peak strength was 0.366 and $0.851 \mathrm{MPa}$ under the curing age of $1 \mathrm{~d}$ and $3 \mathrm{~d}$, respectively. Similarly, under the curing ages of $7 \mathrm{~d}, 14 \mathrm{~d}, 28 \mathrm{~d}$, and $60 \mathrm{~d}$, the average peak strengths of the SCPB were 1.839, 2.909, 4.10 , and $5.54 \mathrm{MPa}$, respectively. As the curing age increased, the peak stress of the SCPB without doped glass fibers gradually increased. As compared with the average peak stress at the curing age of $1 \mathrm{~d}$, the average peak stress at the curing ages of $3 \mathrm{~d}, 7 \mathrm{~d}, 14 \mathrm{~d}, 28 \mathrm{~d}$, and $60 \mathrm{~d}$ increased by 1.32 , $5.02,7.95,11.2$, and 15.1 times, respectively.

The doped glass fibers' influence on the strength of the SCPB with different curing ages was comparatively analyzed. Stress-strain curves of the SCPB doped with glass fibers under different curing ages are plotted in Figure 10.

As shown in Figure 10, the peak compressive strength of the SCPB doped with glass fibers was significantly higher than that of the SCPB without them. One specimen was excluded due to outliers' appearance at curing ages of $1 \mathrm{~d}$, $3 \mathrm{~d}$, and $7 \mathrm{~d}$. Thus, the average was taken of the two specimens under these three curing ages, respectively. The average values were $2.851,3.216$, and $3.845 \mathrm{MPa}$, respectively. As the curing age was increased to $14 \mathrm{~d}, 28 \mathrm{~d}$, and $60 \mathrm{~d}$, the peak compressive strength of the SCPB grew to 4.034, 4.93, and $6.648 \mathrm{MPa}$, respectively. As compared to the average 


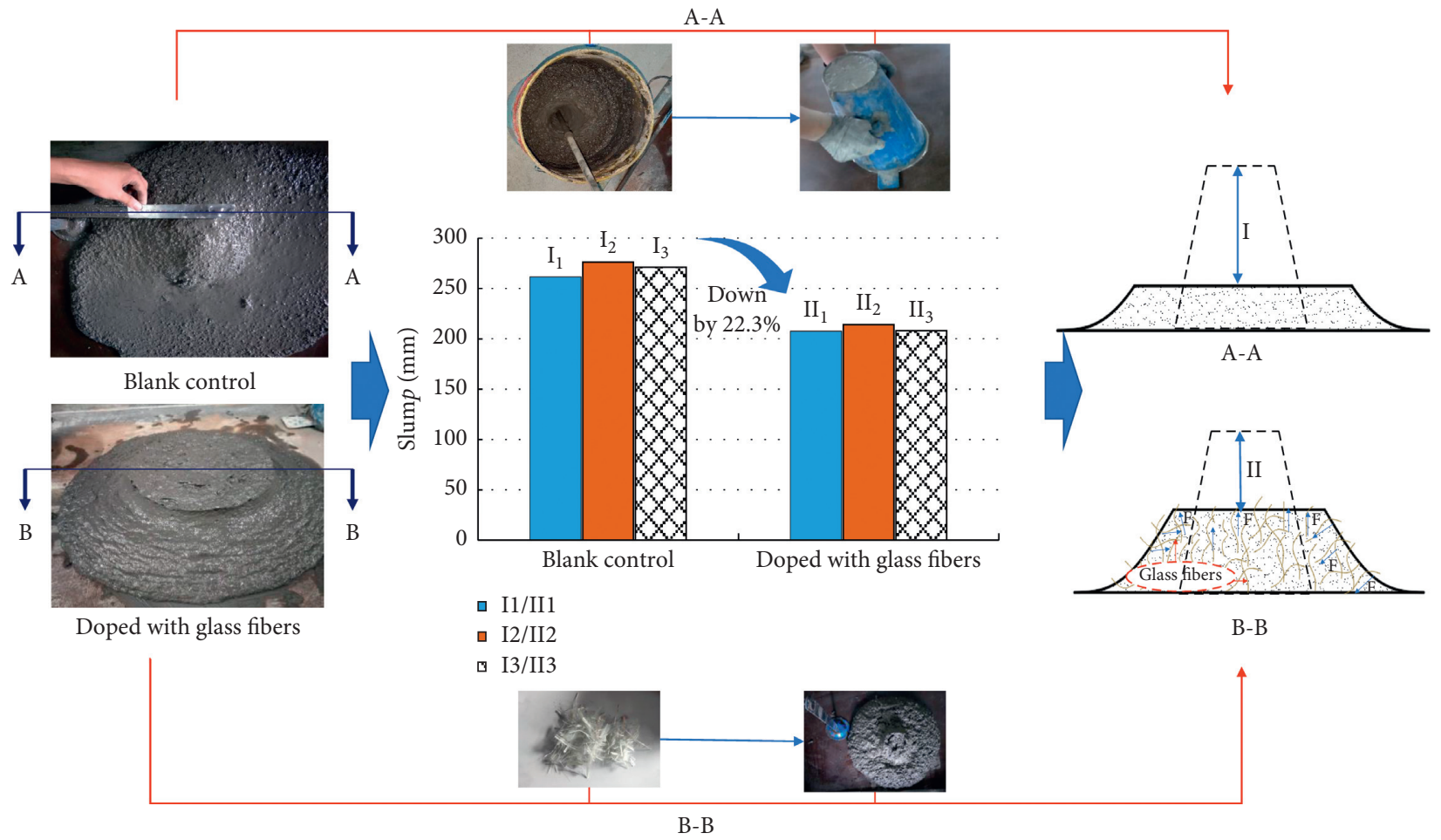

FIgURE 8: Schematic diagram of the influence mechanism of doped glass fibers on the slump.
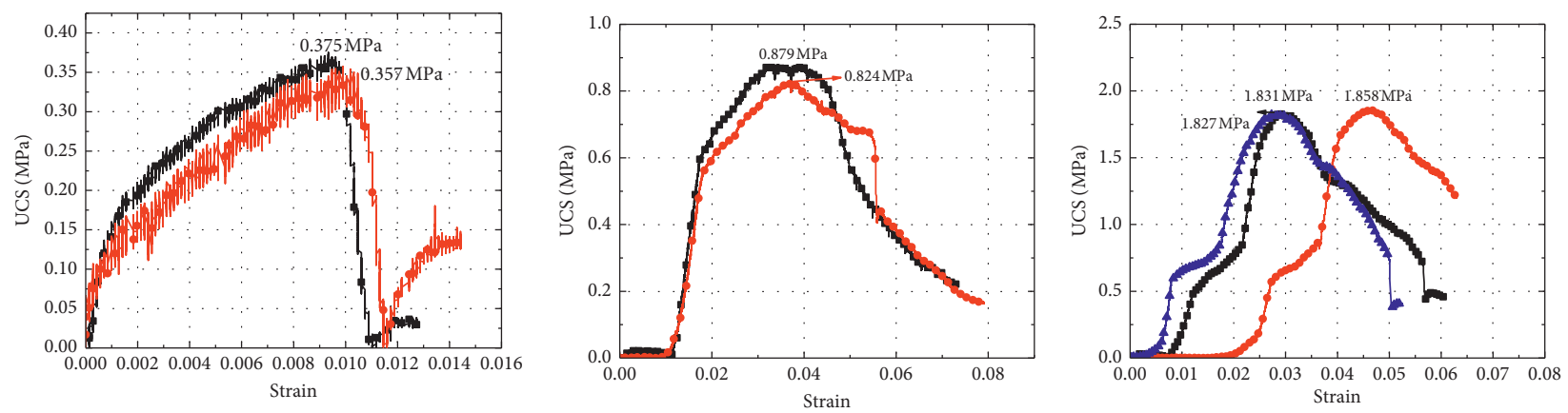

$\rightarrow \mathrm{I}_{\mathrm{u} 1}-1 \mathrm{~d}$

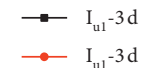

(b)

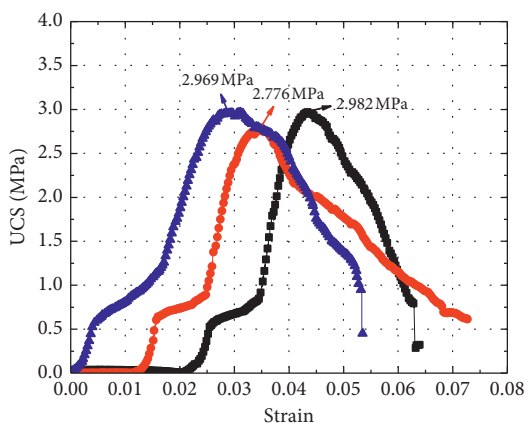

$$
\begin{aligned}
& \rightarrow \mathrm{I}_{\mathrm{u} 1}-14 \mathrm{~d} \\
& \rightarrow \mathrm{I}_{\mathrm{u} 2}-14 \mathrm{~d} \\
& \leftarrow \mathrm{I}_{\mathrm{u} 3}-14 \mathrm{~d}
\end{aligned}
$$

(d)

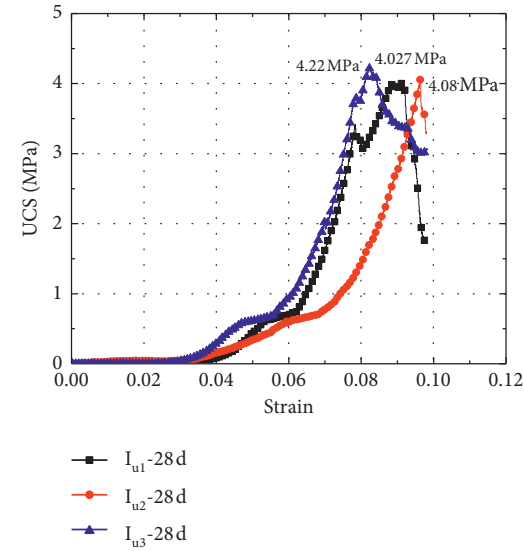

(e)

$$
\begin{aligned}
& \rightarrow \mathrm{I}_{\mathrm{u} 1}-7 \mathrm{~d} \\
& \rightarrow-\mathrm{I}_{\mathrm{u} 2}-7 \mathrm{~d} \\
& \rightarrow \mathrm{I}_{\mathrm{u} 3}-7 \mathrm{~d}
\end{aligned}
$$

(c)

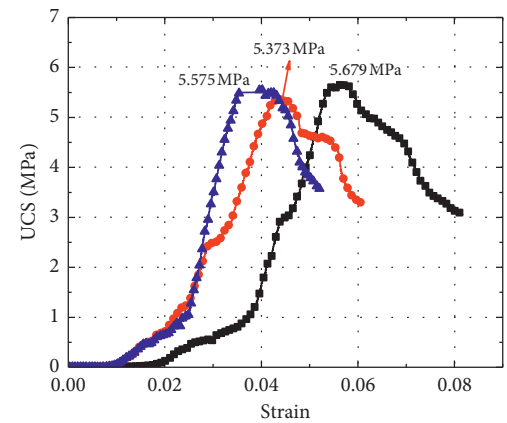

$\rightarrow \mathrm{I}_{\mathrm{u} 1}-60 \mathrm{~d}$
$\rightarrow \mathrm{I}_{\mathrm{u} 2}-60 \mathrm{~d}$
$\rightarrow \mathrm{I}_{\mathrm{u}-}-60 \mathrm{~d}$

(f)

FIGURE 9: Mechanical strength of SCPB with different curing ages (blank control group I). (a) I u-1 d. (b) Iu-3 d. (c) Iu-7 d. (d) Iu-14 d. (e) Iu28 d. (f) Iu-60 d. 


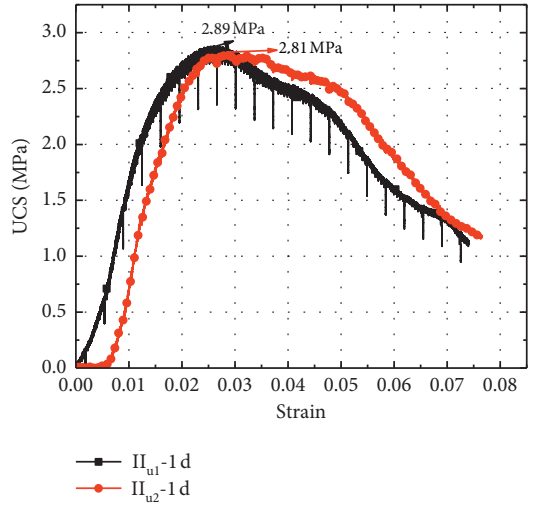

(a)

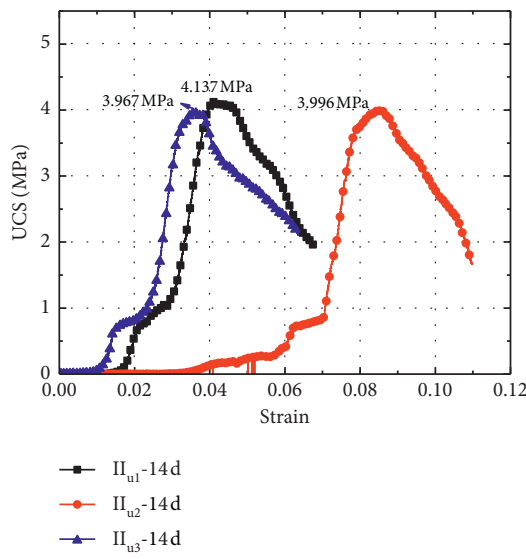

(d)

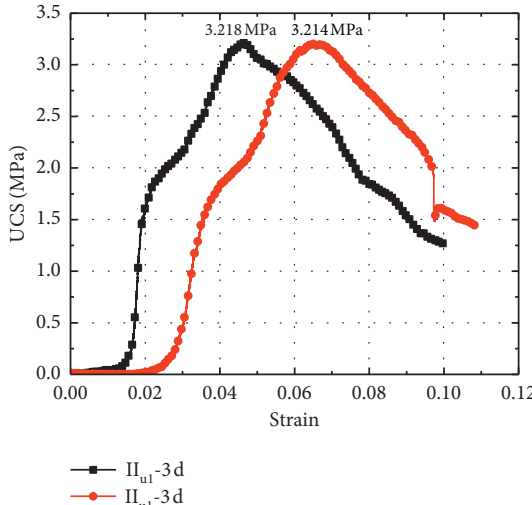

(b)

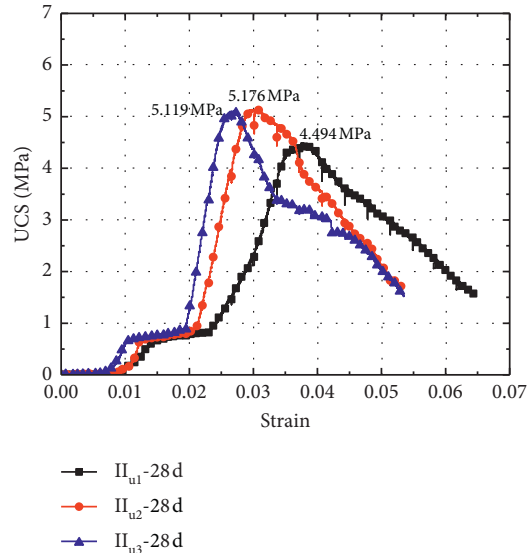

(e)

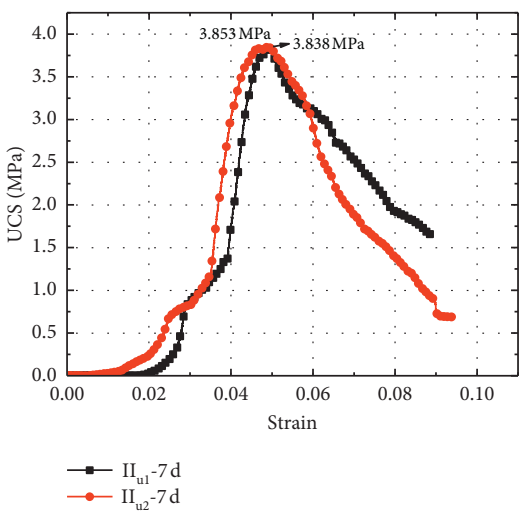

(c)

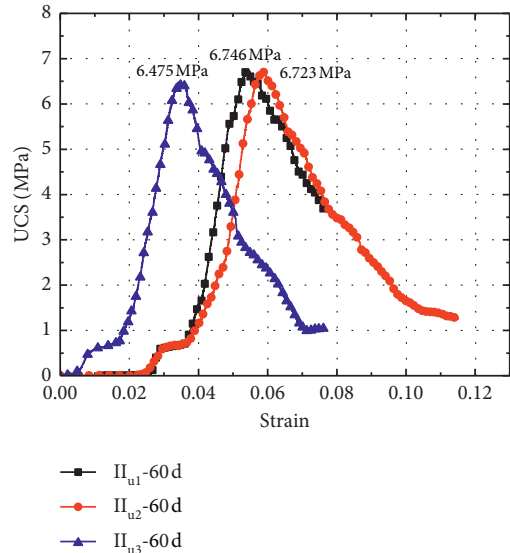

(f)

FIGURE 10: Mechanical strength of SCPB with different curing ages (glass fiber group II). (a) IIu-1 d. (b) IIu-3 d. (c) IIu-7 d. (d) IIu-14 d. (e) IIu-28 d. (f) IIu-60 d.

peak stress at the curing age of $1 \mathrm{~d}$, the average peak stress of the SCPB increased by $0.128,1.35,1.41,1.73$, and 2.3 times at curing ages of $3 \mathrm{~d}, 7 \mathrm{~d}, 14 \mathrm{~d}, 28 \mathrm{~d}$, and $60 \mathrm{~d}$, respectively.

\subsubsection{A Comparative Analysis of the Influence of the Doped} Glass Fibers on the Curing Age. The evolution patterns of the peak compressive strength of the SCPB with different curing ages were analyzed. The peak compressive strength values of the SCPB with and without doped glass fibers were compared. The comparative diagram and histogram of the mechanical strength improvement are plotted in Figures 11(a) and 11(b), respectively.

As shown in Figure 11(a), the blank control group's peak compressive strength at the curing age of $1 \mathrm{~d}$ was equal to $0.366 \mathrm{MPa}$. The peak compressive strength of the SCPB doped with glass fibers was $2.851 \mathrm{MPa}$, and its improvement was $679 \%$. The peak compressive strength of the SCPB doped with glass fibers was 7.8 times higher than that of the SCPB without them at the curing age of $1 \mathrm{~d}$. The peak compressive strength of the SCPB without doped glass fibers was $0.851 \mathrm{MPa}$ at the curing age of $3 \mathrm{~d}$. The respective peak compressive strength of the SCPB doped with glass fibers was $3.216 \mathrm{MPa}$, and the improvement was $278 \%$. As the curing age gradually increased, the peak compressive strength improvement rate of the SCPB doped with glass fibers gradually decreased. At curing ages of $14 \mathrm{~d}, 28 \mathrm{~d}$, and $60 \mathrm{~d}$, the peak compressive strength values of the SCPB gradually stabilized, as shown in Figure 11(b). When the curing age increased to $7 \mathrm{~d}, 14 \mathrm{~d}, 28 \mathrm{~d}$, and $60 \mathrm{~d}$, the peak compressive strength of the SCPB specimens doped with glass fibers increased by 109, 39, 20, and $20 \%$, respectively. This was mainly because the SCPB bearing capacity at the early stage of its formation remained quite low. The doped glass fibers inhibited the SCPB deformation, thereby improving its bearing capacity. However, as the curing age of the SCPB gradually increased, the inside of the SCPB solidified. The compressive strength of the SCPB increased correspondingly. When subjected to external stress, the SCPB withstood a more significant portion of the stress, while the glass fibers exerted little influence on its compressive strength. As the curing age continued to increase, the SCPB response and the peak strength stabilized and saturated.

\subsection{Influence Mechanism of Doped Glass Fibers on the SCPB Microstructure}

3.3.1. Microstructural Features of SCPB Specimens with Different Curing Ages. We further verified the effect of glass fibers on the early compressive strength of the SCPB by 


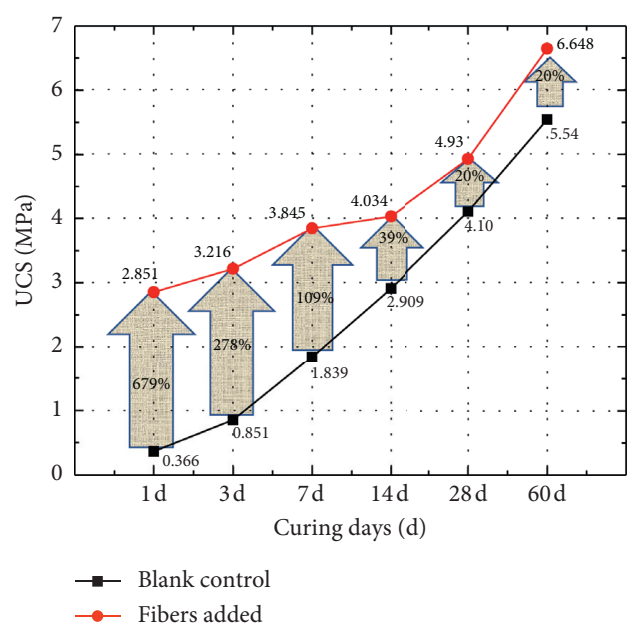

(a)

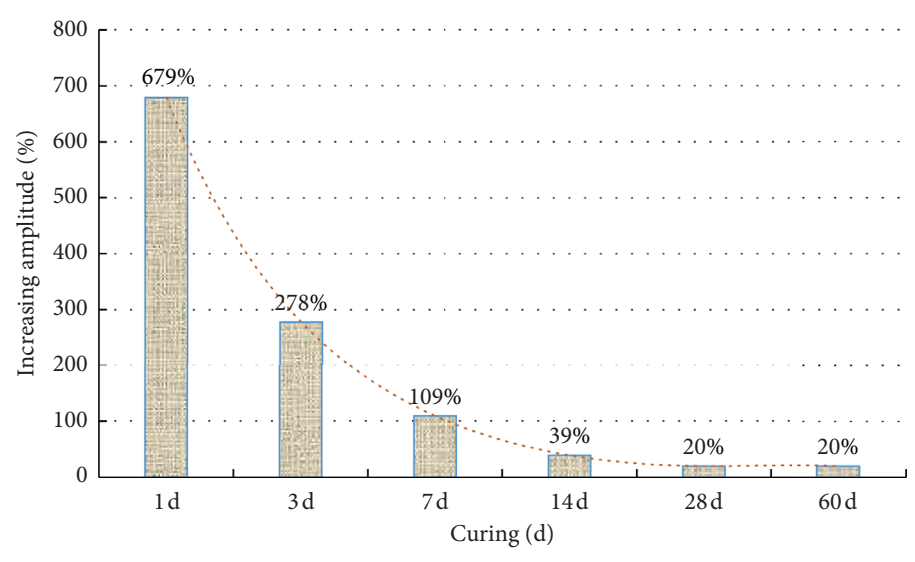

(b)

FIGURE 11: Comparison of the compressive strength improvement. (a) Comparative analysis of the mechanical strength improvement. (b) Histogram of the mechanical strength improvement.

revealing the influence mechanism of glass fibers on the SCPB microstructure at different curing ages. The SEM analysis was performed to assess the SCPB microstructure at different curing ages. The observation results are presented in Figures 12-14 for curing ages of $1 \mathrm{~d}, 14 \mathrm{~d}$, and $60 \mathrm{~d}$, respectively.

Figures 12(a) and 12(b) were compared. At a $10 \mathrm{~d}$ curing age, the observation of the SCPB at $40 \times$ magnification revealed that the SCPB without doped glass fibers had a smooth surface. The lapping force between the SCPB structures was small, which led to cracking under a lower bearing capacity and, hence, to failure. In Figure 12(a), the SCPB doped with fibers had a rough surface, with the structures' glass fibers embedded. The glass fibers exhibited a crosslink distribution pattern in the SCPB, connecting the structures within the SCPB into a network. Therefore, the SCPB deformation was inhibited. At the early stage of the SCPB formation, the compressive strength of the SCPB doped with glass fibers was higher than without them.

As shown in Figures 13 and 14, with an increase in curing age, crystal particles and flaky gel formed within the SCPB became stabilized. Their comparison with Figure 11 revealed that the SCPB compressive strength increased correspondingly. Meanwhile, the contribution made by the glass fibers to the compressive strength of the SCPB decreased gradually. As shown in Figures 13(a) and 14(a), when the curing age increased from $14 \mathrm{~d}$ to $60 \mathrm{~d}$, more crystal particles and flaky gel accumulated around the glass fibers. These crystal particles were suspended in the slurry to reduce the aggregate particles' friction, thereby inhibiting large particles' deposition. The flaky gel attached itself to the fly ash particles' surfaces and glass fibers and immobilized the latter in the SCPB. In this way, glass fibers and SCPB constituted an integral structure. In Figures 13(b) and 14(b), as the curing age increased, the gaps between the particles in the SCPB gradually decreased. The degree of internal structural compaction increased, and therefore the SCPB compressive strength increased as well.
At the early forming stage of SCPB, the hydration reaction's intensity was low and so did to bearing capacity of $\mathrm{SCPB}$. At this stage, glass fibers contributed more significantly to the compressive strength of the SCPB. As the curing age increased, the hydration reaction in SCPB was intensified, resulting in a gradual improvement of its mechanical strength. Glass fibers were immobilized in the $\mathrm{SCPB}$, and they influenced the compressive strength of SCPB less significantly. The stress resistance of the SCPB primarily came from its bearing capacity.

\section{Discussion}

4.1. Comparative Analysis of the Correlation between the Macroscopic and Microscopic Properties of the SCPB Specimens under Different Curing Ages. The microstructure of SCPB doped with glass fibers at curing ages of $1 \mathrm{~d}, 3 \mathrm{~d}, 14 \mathrm{~d}$, and $60 \mathrm{~d}$ was analyzed to study the correlation between microscopic and macroscopic properties of the doped SCPB at various curing ages. The reason for choosing only these four curing ages was that the distribution pattern in the SCPB was consistent as the curing age increased. Figure 15 shows the correlation between microscopic and macroscopic properties of the blank control group and the SCPB doped with glass fibers.

As seen in Figure 15, the hydration reaction in the SCPB intensified with the curing age. The internal structure was loose initially and became more compact over time. As the curing age increased to $28 \mathrm{~d}$ and $60 \mathrm{~d}$, there was a small difference in the compressive strengths of the blank control group and the SCPB doped with glass fibers. The compressive strength increased gradually with curing age. At the curing ages of $1 \mathrm{~d}$ and $3 \mathrm{~d}$, the peak compressive strength of the SCPB doped with glass fibers was significantly higher than that of the blank control group. As observed from the microstructures at curing ages of $1 \mathrm{~d}$ and $3 \mathrm{~d}$, glass fibers acted as bridges in the SCPB. At these two curing ages, the compressive strength of the SCPB was relatively low. The 


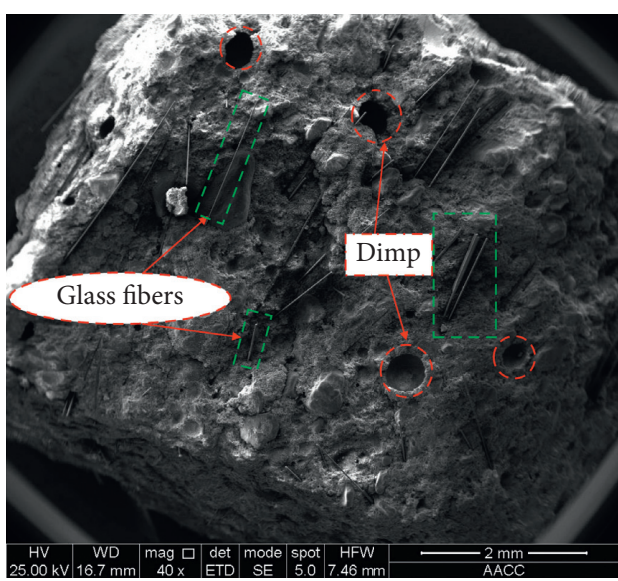

(a)

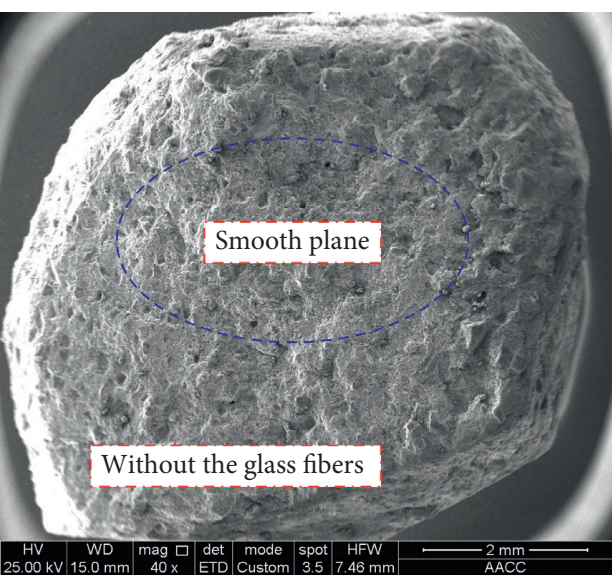

(b)

FIGURE 12: The microstructure of SCPB specimens with and without doped glass fibers at a 1d curing age. (a) With glass fibers. (b) Without glass fibers.

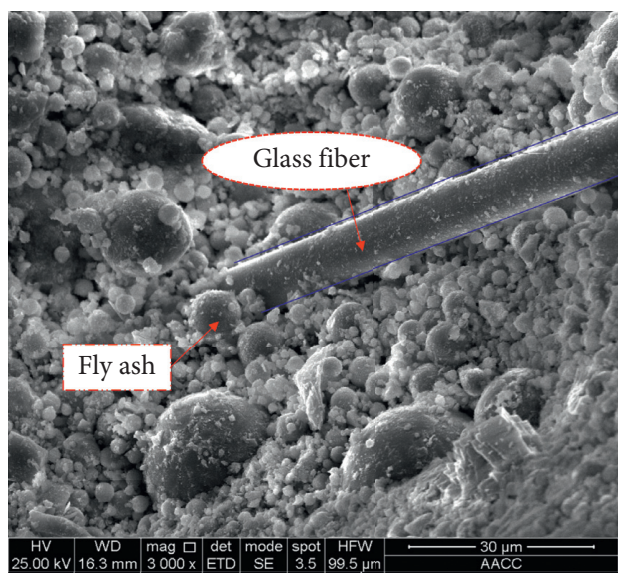

(a)

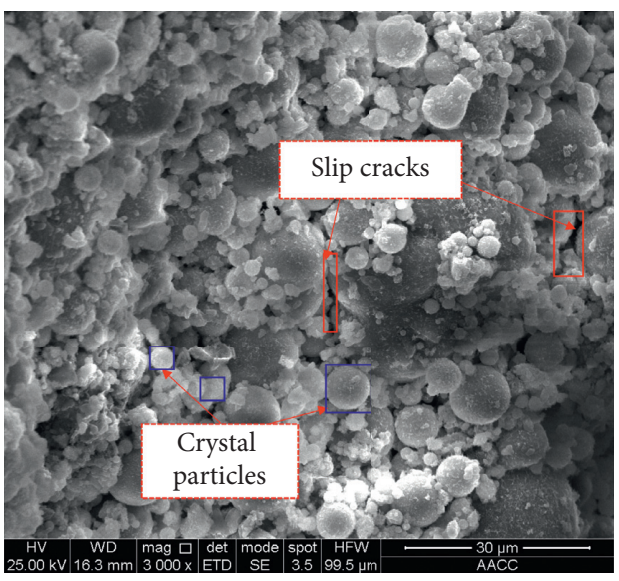

(b)

FIGURE 13: The microstructure of SCPB specimens with and without doped glass fibers at a $14 \mathrm{~d}$ curing age. (a) With glass fibers. (b) Without glass fibers.

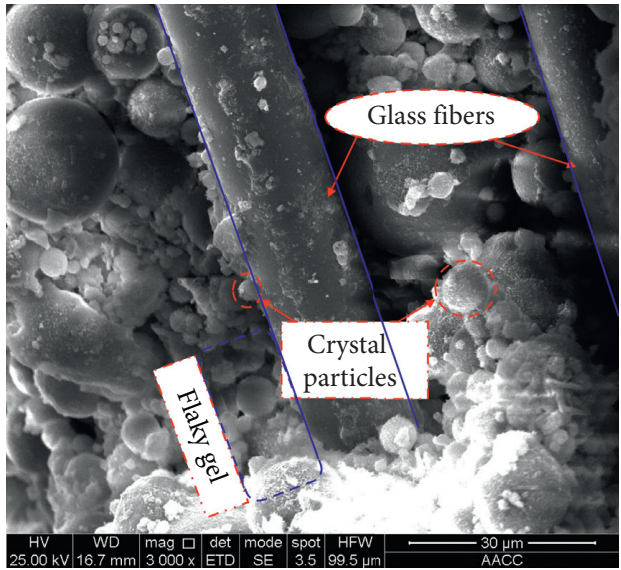

(a)

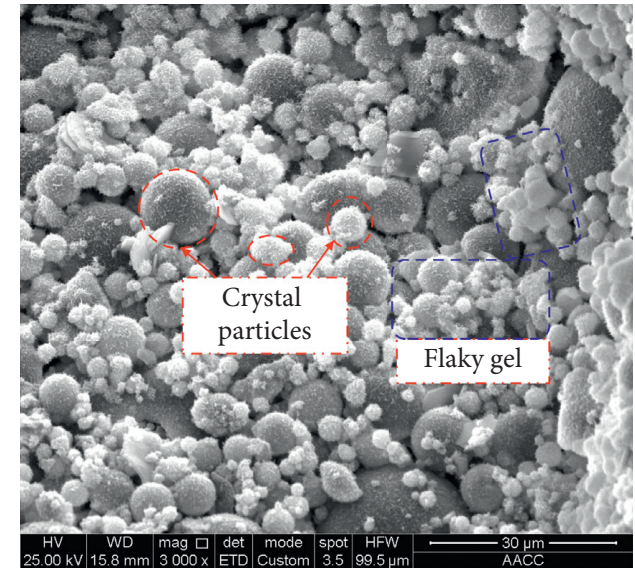

(b)

FIGURE 14: The microstructure of SCPB specimens with and without doped glass fibers at a $60 \mathrm{~d}$ curing age. (a) With glass fibers. (b) Without glass fibers. 


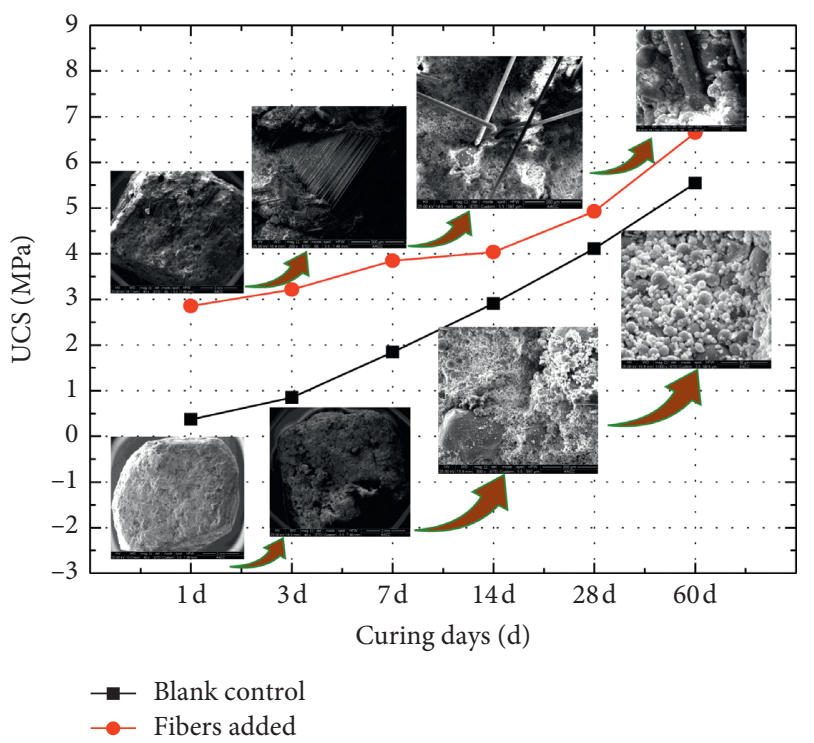

FIGURE 15: Correlation between macroscopic and microscopic properties of SCPB specimens.
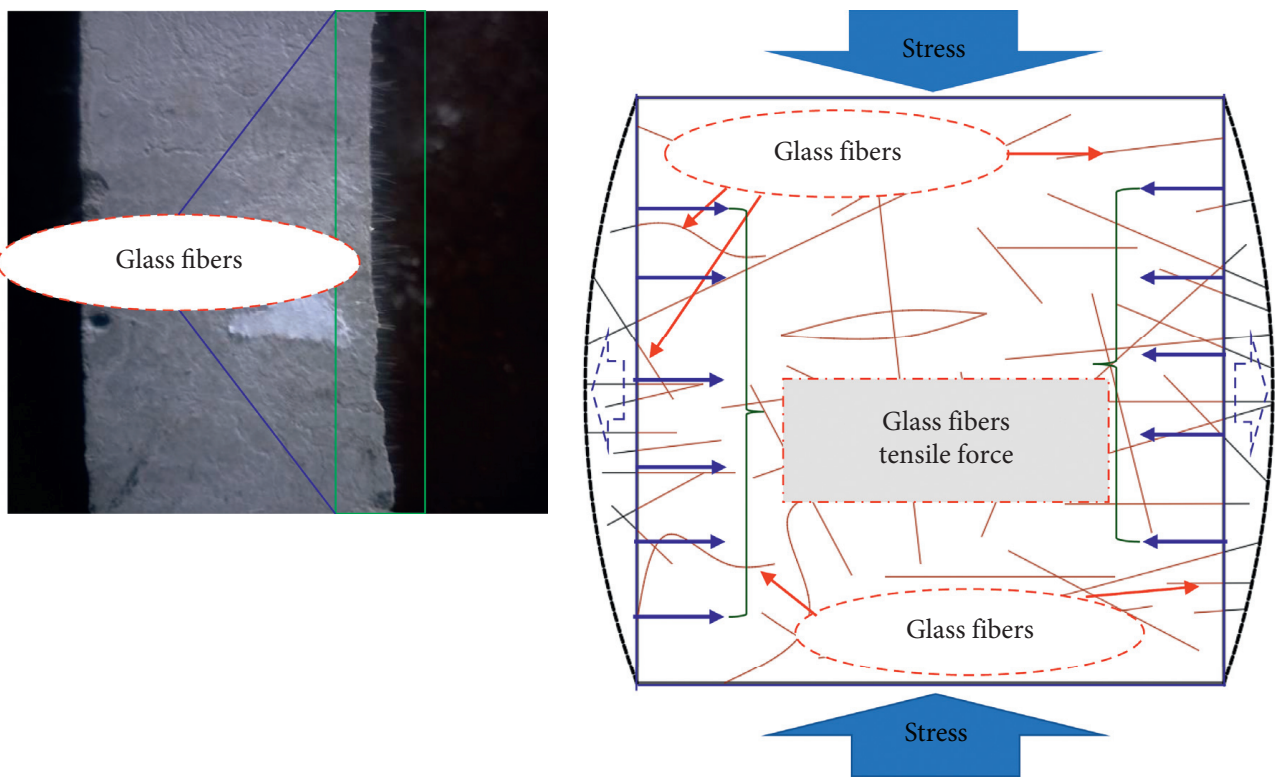

(a)

(b)

FIgURE 16: Schematic diagram of the increase in mechanical performance. (a) Photo of the specimen's inner surface. (b) Schematic diagram of the stress acting on the specimen.

glass fibers ran through the SCPB bulk, offering deformation resistance and increasing its early compressive strength.

4.2. Influence Mechanism of Doped Glass Fibers on the Early Strength of SCPB. Figure 16 shows the schematic diagram of the early compressive strength of the SCPB doped with glass fibers.

As shown in Figure 16(a), glass fibers exhibited a crosslink distribution pattern in the SCPB, running through its bulk. According to the stress diagram in Figure 16(b),
SCPB had insufficient strength at the early forming stage, so its bearing capacity was quite low. The SCPB underwent creep deformation under the squeezing action of the overlying strata. As the SCPB dilated under stress, the crosslinked fibers inside the SCPB exerted a force acting in the opposite direction to the SCPB deformation, inhibiting it and improving the early compressive strength of SCPB.

With an increase in curing age, the hydration reaction occurred continuously in the SCPB, resulting in a gradual improvement of its bearing capacity. When the stress borne by the SCPB exceeded its bearing capacity limit, the failure 
mode was no longer the creep deformation. At this time, the glass fibers influenced the peak compressive strength of the SCPB less significantly. Thus, the SCPB doping with glass fibers significantly improved its early compressive strength. With an increase in curing age, the hydration reaction stopped, and the glass fibers influenced the compressive strength of the SCPB less significantly. Thus, the early compressive strength of the SCPB doped with glass fibers increased steadily.

\section{Conclusions}

Glass fibers with a length of $6 \mathrm{~mm}$ were doped into the SCPB with a ratio of $1.0 \%$. The influence mechanism of glass fibers on the SCPB compressive strength at various curing ages, in particular, the early strength, was clarified. The following findings were made:

(1) Glass fibers had a significant impact on the flowability of the SCPB slurry. That is, the average slump size of the SCPB without doped glass fibers was $269 \mathrm{~mm}$. After doping with glass fibers, the average slump of the SCPB was $209 \mathrm{~mm}$; i.e., its size dropped by $22.3 \%$. Besides, glass fibers exerted a tensile force $\mathrm{F}$ on the SCPB slurry opposite to the SCPB slurry flow. Thus, the glass fibers' presence effectively inhibited the slurry's dispersion and flowability, thereby reducing the slump of the SCPB doped with glass fibers.

(2) The glass fibers significantly improved the SCPB's early strength. At curing ages of $1 \mathrm{~d}$ and $3 \mathrm{~d}$, the compressive strength of SCPB specimens with doped glass fibers improved by 679 and $278 \%$, respectively. As the curing age gradually increased, the above improvement became saturated. That is, at curing ages of $28 \mathrm{~d}$ and $60 \mathrm{~d}$, the peak compressive strength values were both $20 \%$, indicating a stabilizing trend.

(3) At the early forming stage, the bearing capacity of SCPB remained low. It underwent deformation under the squeezing action of the overlying strata. As the SCPB dilated under stress, the cross-linked fibers inside the SCPB exerted a force acting in the opposite direction to the SCPB deformation. This further inhibited the deformation and improved the early compressive strength of SCPB.

(4) As the curing age increased, the hydration reaction in SCPB was intensified, resulting in solidification of the cement and a gradual improvement of its mechanical strength. Glass fibers were immobilized in the SCPB, which reduced their effect on the SCPB compressive strength. Given this, the SCPB stress resistance at later curing ages primarily came from its bearing capacity.

\section{Data Availability}

The data used to support the findings of this study are included within the article.

\section{Conflicts of Interest}

The authors declare that they have no conflicts of interest.

\section{Authors' Contributions}

All the authors contributed to this paper. Cunli Zhu and Nan Zhou participated in the design of this study; Cunli Zhu contributed to writing this manuscript and organizing all the experiments; Nan Zhou contributed to drafting the manuscript; Meng Li contributed to the sample making; Jixiong Zhang and Zhiwei He reviewed the final paper and made important suggestions and recommendations.

\section{Acknowledgments}

This research was financially supported by the National Natural Science Foundation of China (51874287 and 52004271), the Fundamental Research Funds for the Central Universities (2021YCPY0105), the Independent Research Project of State Key Laboratory of Coal Resources and Safe Mining, and CUMT (SKLCRSM19X006).

\section{References}

[1] N. Jiang, C. Wang, H. Pan, D. Yin, and J. Ma, "Modeling study on the influence of the strip filling mining sequence on mining-induced failure," Energy Science \& Engineering, vol. 8, no. 6, pp. 2239-2255, 2020.

[2] X. J. Deng, Z. X. Yuan, Y. Li, H. Liu, J. Y. Feng, and B. Wit, "Experimental study on the mechanical properties of microbial mixed backfill," Construction and Building Materials, vol. 265, pp. 120-643, 2020.

[3] S. J. Chen, H. L. Wang, W. J. Guo, and X. S. Li, "Strip coal pillar design based on estimated surface subsidence in Eastern China," Rock Mechanics and Rock Engineering, vol. 49, pp. 3829-3838, 2016.

[4] N. Zhou, H. Ma, S. Ouyang, D. Germain, and T. Hou, "Influential factors in transportation and mechanical properties of aeolian sand-based cemented filling material," Minerals, vol. 9, no. 2, p. 116, 2019.

[5] Q. Sun, J. Zhang, and N. Zhou, "Early-age strength of aeolian sand-based cemented backfilling materials: experimental results," Arabian Journal for Science and Engineering, vol. 43, no. 4, pp. 1697-1708, 2018.

[6] X. Deng, J. Zhang, B. Klein, N. Zhou, and B. deWit, "Experimental characterization of the influence of solid components on the rheological and mechanical properties of cemented paste backfill," International Journal of Mineral Processing, vol. 168, pp. 116-125, 2017.

[7] B. Y. Li and F. Ju, "An experimental investigation into the compaction characteristic of granulated gangue backfilling materials modified with binders," Environmental Earth Sciences, vol. 77, p. 284, 2018.

[8] N. Zhou, H. Yan, S. Jiang, Q. Sun, and S. Ouyang, "Stability analysis of surrounding rock in paste backfill recovery of residual room pillars," Sustainability, vol. 11, no. 2, p. 478, 2019.

[9] N. Zhou, S. Y. Ouyang, Q. Q. Cheng, and F. Ju, "Experimental study on mechanical behavior of a new backfilling material: cement-treated marine clay," Advances in Materials Science and Engineering, vol. 2019, Article ID 1261694, 8 pages, 2019. 
[10] B. Y. Zhou, L. Wang, G. W. Ma, X. Zhao, and X. H. Zhao, "Preparation and properties of bio-geopolymer composites with waste cotton stalk materials," Journal of Cleaner Production, vol. 245, Article ID 118842, 2020.

[11] D.-L. Wang, Q.-L. Zhang, Q.-S. Chen, C.-C. Qi, Y. Feng, and C.-C. Xiao, "Temperature variation characteristics in flocculation settlement of tailings and its mechanism," International Journal of Minerals, Metallurgy and Materials, vol. 27, no. 11, pp. 1438-1448, 2020.

[12] M. Li, J. X. Zhang, G. H. Meng, Y. Gao, and A. L. Li, “Testing and modelling creep compression of waste rocks for backfill with different lithologies," International Journal of Rock Mechanics and Mining Sciences, vol. 125, pp. 104-170, 2020.

[13] X. Deng, B. Klein, L. Tong, and B. De Wit, "Experimental study on the rheological behavior of ultra-fine cemented backfill," Construction and Building Materials, vol. 158, pp. 985-994, 2018.

[14] M. Li, J. X. Zhang, A. L. Li, and N. Zhou, "Reutilisation of coal gangue and fly ash as underground backfill materials for surface subsidence control," Journal of Cleaner Production, vol. 254, Article ID 120113, 2020.

[15] M. Li, J. Zhang, N. Zhou, and Y. Huang, "Effect of particle size on the energy evolution of crushed waste rock in coal mines," Rock Mechanics and Rock Engineering, vol. 50, no. 5, pp. 1347-1354, 2017.

[16] X. W. Yi, G. W. Ma, and A. Fourie, "Centrifuge model studies on the stability of fibre-reinforced cemented paste backfill stopes," Geotextiles and Geomembranes, vol. 46, no. 4, pp. 396-401, 2018.

[17] J. H. Hu, Q. F. Ren, Q. Jiang, R. G. Gao, L. Zhang, and Z. Q. Luo, "Strength characteristics and the reaction mechanism of stone powder cement tailings backfill," Advances in Materials Science and Engineering, vol. 2018, Article ID 8651239, , 2018.

[18] Y.-Y. Tan, E. Davide, Y.-C. Zhou, W.-D. Song, and X. Meng, "Long-term mechanical behavior and characteristics of cemented tailings backfill through impact loading," International Journal of Minerals, Metallurgy and Materials, vol. 27, no. 2, pp. 140-151, 2020.

[19] Y. He, Q. L. Zhang, Q. S. Chen et al., "Mechanical and environmental characteristics of cemented paste backfill containing lithium slag-blended binder," Construction and Building Materials, vol. 271, Article ID 121567, 2021.

[20] X. J. Deng, J. X. Zhang, N. Zhou, B. Dewit, and C. T. Wang, "Upward slicing longwall-roadway cemented backfilling technology for mining an extra-thick coal seam located under aquifers: a case study," Environmental Earth Sciences, vol. 76, p. 789, 2017.

[21] N. Li, S. W. Lv, W. Wang, J. Guo, P. Jiang, and Y. Liu, "Experimental investigations on the mechanical behavior of iron tailings powder with compound admixture of cement and nano-clay," Construction and Building Materials, vol. 254, Article ID 119259, 2020.

[22] Y. Feng, Q. S. Chen, Y. L. Zhou et al., "Modification of glass structure via $\mathrm{CaO}$ addition in granulated copper slag to enhance its pozzolanic activity," Construction and Building Materials, vol. 240, Article ID 117970, 2020.

[23] N. Zhou, J. X. Zhang, S. Y. Ouyang, X. J. Deng, C. W. Dong, and E. B. Du, "Feasibility study and performance optimization of sand-based cemented paste backfill materials," Journal of Cleaner Production, vol. 259, Article ID 120798, 2020.

[24] T. Yilmaz, B. Ercikdi, and H. Deveci, "Utilisation of construction and demolition waste as cemented paste backfill material for underground mine openings," Journal of Environmental Management, vol. 222, pp. 250-259, 2018.

[25] A. Sivakumar and M. Santhanam, "Mechanical properties of high strength concrete reinforced with metallic and nonmetallic fibres," Cement and Concrete Composites, vol. 29, no. 8, pp. 603-608, 2007.

[26] L. Lassila, F. Keulemans, E. Säilynoja, P. K. Vallittu, and S. Garoushi, "Mechanical properties and fracture behavior of flowable fiber reinforced composite restorations," Dental Materials, vol. 34, no. 4, pp. 598-606, 2018.

[27] Y. J. Zhang, A. R. Liu, B. C. Chen, J. P. Zhang, Y. L. Pi, and M. A. Bradford, "Experimental and numerical study of shear connection in composite beams of steel and steel-fibre reinforced concrete," Engineering Structures, vol. 215, Article ID 110707, 2020.

[28] J. Liu, Y. X. Bai, Z. Z. Song et al., "Stabilization of sand using different types of short fibers and organic polymer," Construction and Building Materials, vol. 253, Article ID 119164, 2020.

[29] Y. W. D. Tay, Y. Qian, and M. J. Tan, "Printability region for 3D concrete printing using slump and slump flow test," Composites Part B: Engineering, vol. 174, Article ID 106968, 2019. 